\title{
Computational Modeling of the Hydraulic Jump in the Stilling Basin with Convergence Walls Using CFD Codes
}

\author{
Hamidreza Babaali · Abolfazl Shamsai • \\ Hamidreza Vosoughifar
}

Received: 9 February 2014 / Accepted: 25 October 2014 / Published online: 5 December 2014

(C) The Author(s) 2014. This article is published with open access at Springerlink.com

\begin{abstract}
The stilling basin has been accepted to be the most powerful hydraulic structure for the dissipation of the flow energy. The size and geometry of the stilling basin affect the formation of flow patterns, which can be influential for hydraulic performance of the whole system. The Nazloo Dam in Iran was selected as the study area. The USBR II stilling basin was conducted for four convergence angles $\left(5^{\circ}, 7.5^{\circ}, 10^{\circ}\right.$, and $\left.12.5^{\circ}\right)$. The convergence walls cause the jump to stabilize inside the basin and cause the energy loss to increase in the stilling basin. To simulate the hydraulic jump in the convergence stilling basin conditions in this region, a free surface computational fluid dynamics (CFD) numerical model has been applied. The commercially known software, FLOW-3D ${ }^{\circledR}$, was applied to numerically solve the NavierStokes equations for solution domains, namely the shout, the stilling basin and the downstream of dam, and to estimate the turbulence flow, the standard $\mathrm{k}-\varepsilon$ and RNG models was used. These models are based on the volume-of-fluid method, and they are capable of simulating the hydraulic jump. The calculated results such as the pressure, the velocities, the flow rate, the surface height air entranced, the kinetics energy, the kinetics energy dissipated, and the Froude number were compared with the scale model data where available. This allowed a comparison for the use of CFD as a cost-effective alternative to physical models. The physical model and CFD model results showed good correlations.
\end{abstract}

H. Babaali $(\varangle) \cdot$ A. Shamsai

Department of Civil Engineering, Science and Research Branch,

Islamic Azad University, Tehran, Iran

e-mail: ham_babaali@yahoo.com

H. Vosoughifar

Department of Civil Engineering, South Tehran Branch,

Islamic Azad University, Tehran, Iran
Keywords The stilling basin - The hydraulic jump . CFD model $\cdot$ The turbulent model $\cdot$ The finite volume

\section{Introduction}

When the depth of flow changes rapidly from a low stage to a high stage due to a decrease in velocity, the result is an abrupt rise of the water surface. This local phenomenon is known as the hydraulic jump. The hydraulic jumps are commonly used as energy dissipaters, and they have been studied intensively by hydraulic engineers mainly through laboratory experiments. In the jump, the water surface rises abruptly, causing great agitation. A re-circulating roller is present near the surface with an intense mixing of air, starting from high Froude number $F_{r 1}$. Energy dissipaters are one of the most important parts of high dams of these structures; the stilling basins are used extensively to reduce the destructive energy of the water, passing down the spillway of high dams [1,2].

\subsection{Laboratory and Field Studies}

Most studies of the hydraulic jump were conducted to obtain laboratory and empirical data. Bidone was the pioneer to conduct investigations on the hydraulic jump in 1818-1819. In 1828 , Belanger developed the momentum equation connecting the sequent depths (Bresse, Darcy and Bazin, Uniwin, Ferriday and Merriman, Gibson, Kennison, Woodward and Riegel Beebe, Koch and Cartstanjen, Lindquist, Safranez, Einwachter, Smetana, Bakhmeteff and Matzke, Escande, Citrini, Nebbia, Kindsvater, Blaisdell, Forster and Skrinde, Moore and Morgan, and Rouse et al., Rajaratnam, Peterka, Hager) have conducted laboratory research in the area [3]. 


\subsection{The Numerical Studies}

A relatively large volume of data are available from many laboratory and field studies performed in the past. Some of the studies were done on the basis of semi-analysis solutions [4]. Chow [5] achieved the water surface profile for the over critical flow by starting the calculations from the end of upstream and the subcritical flow by starting the calculations from the end of downstream and the identification of jump location by putting the specific force in two sides [5].

In order to reach stability conditions, Abbott et al. [6] used the finite difference, and Katopodes [7] used the finite element method to solve Saint Venant equations. In order to solve the Saint Venant equation, they took two false assumptions, namely the pressure hydrostatic distribution and the uniform velocity distribution [6,7].

One of the old studies regarding the numerical solution was done by Hibberd and Peregrine in 1979, in which the schematic plan of Lax-Wendorf was used to determine the flow loss $[7,8]$.

In order to calculate the length of the jump, the velocity profile, and the pressure at the bottom of channel, McCorquodale and Khalifa started the numerical solution of the hydraulic jump through the integration method [9].

Basco et al. [10] and McCown et al. [11] considered another assumption for the numerical solution as the velocity is varied from zero at the bottom of channel to the maximum value in a surface. Their equations originate from the Boussinesq equation rooted as nonlinear equations of differential. If the non-hydrostatic pressure term is ignored in the Boussinesq equations, we can reach Saint Venant equations. We should say the first-rank and the second-rank numerical plans present acceptable results to solve the rapid varied flow $[10,11]$.

By the standard model k- $\varepsilon$, Long et al. [12] achieved good numerical results. They achieved the underlying equations on the stable flow and used it to determine the free surface slope. Qingchao and Drewes [13] studied some of the turbulence parameters. He solved turbulence conditions under the free hydraulic jump and the pressure by the numerical method $[12,13]$. Based on Boussinesq equations in a rectangular channel by the Mack Cormack approximation and two-four plans, Gharangik and Chaudhry [14] started the hydraulic jump numerical solution.

In 2001, Wang and Liu investigated four methods of finite volumes on non-structure triangle networks, and some problems such as the 2-D solution of shallow water, the dam failure as 2-D, and the oblique hydraulic jump were solved by these four methods, and the numerical solution results, the calculations velocity, and the stability of solution methods were compared [15].

Based on the optimized control issue, Unami et al. [16] investigated the estimation of transport and dissipation coef- ficients of aerated flow in the hydraulic jump [16]. Yoo et al. [17] studied the characteristics of flow field around Soyang Dam by the numerical method. In this simulation, Flow-3D software was used [17]. In 2002, Prinos and Hou studied the characteristics of turbulent flow of the hydraulic jump in submerged conditions by the numerical method via the $\mathrm{k}-\varepsilon$ model. They investigated free surface characteristics by the free surface method [2]. Zhao et al. [18] attempted the hydraulic jump by Navier-Stokes equations. By the VOF technique, they investigated the jump flow turbulence. Also, based on the average jump flow, they started the numerical solution. In their research, the Froude number of less than 2 was evident. They compared their numerical data with the laboratory data by Qingchao and Drewes [13] and Zhao et al. [18]. Zhao and Misra [19] simulated the turbulent hydraulic jump method by numerical methods. The results of horizontal velocity were compared with empirical measurements.

In this paper, the numerical investigations were calculated for the ability of an available 3-D flow solver. Moreover, the fully turbulent aerated flow with free surface has been modeled. In this flow, the hydraulic jump has occurred inside the non-prismatic stilling basin. This kind of flow is very appealing for many researchers on the energy dissipation. The free surface flow in the stilling basin is simulated by means of Flow-3D software. The hydraulic jump property calculations are compared to experimentally obtained values.

\section{The Physical Model}

The hydraulic model of the Nazloo Dam was constructed in the hydromechanics laboratory of Civil Engineering Department at Iran [20,21]. Similitude between the model and the prototype was based on the equality of Froude numbers. From the length ratio, the model scale was found to be $1 / 40$. The length of stilling basin is $43 \mathrm{~m}$, and its width is $30 \mathrm{~m}$. The hydraulic model was placed over a $2 \mathrm{~m}$ high concrete platform with a horizontal area of $7.65 \mathrm{~m} \times 6.10 \mathrm{~m}$ (length $\times$ width) (Fig. 1). The stilling basin model and its other parts such as the chute constructed of transparent Plexiglas and baffle piers were made of wood covered with oily color. The bed level of basin is 1,396, and the river bed level is 1,403 . Based on the map, the topographic surface was constructed up to level 1,415 . The upper level of the stilling basin walls is 1,411 . In order to increase the depth ratio and to stabilize the jump in the basin, in this stage, blocks with equal heights and widths were used [20,21] (Fig. 2).

The distance among the blocks was $2.5 \mathrm{~cm}$. Instead of the end sill, the laboratory used three stairs with $5.7 \mathrm{~cm}$ height ( 2.3 in the real model) and $5 \mathrm{~cm}$ lengths ( $2 \mathrm{~m}$ in the real model) 
(a)

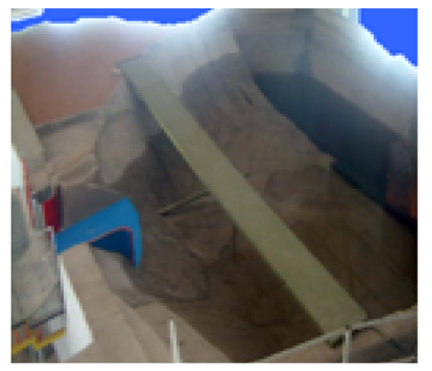

(b)

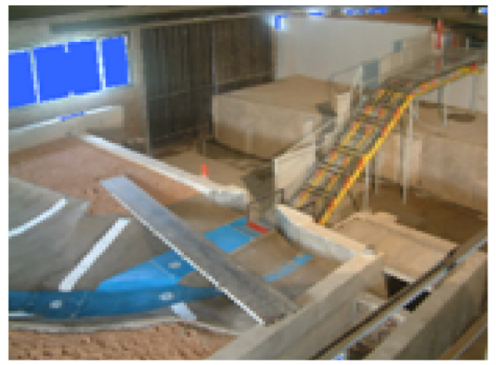

(c)

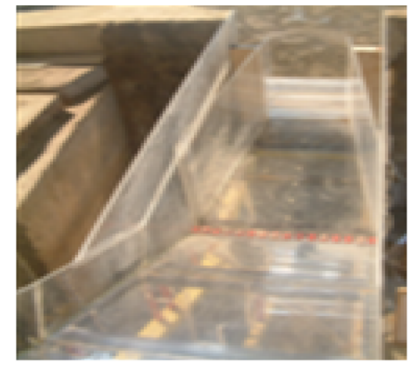

Fig. 1 Model layout in laboratory [20,21]. a Reservoir. b Shout channel. c The convergence stilling basin

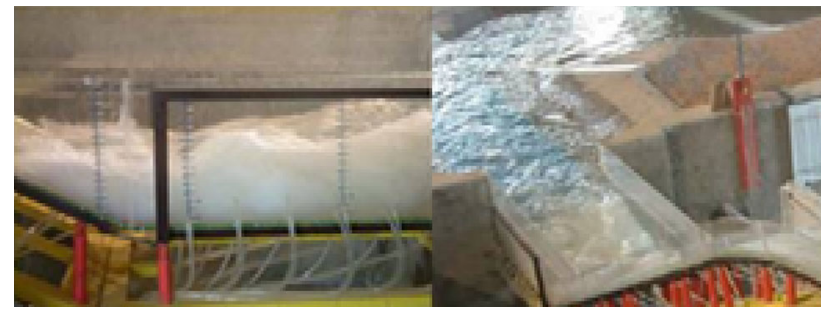

Fig. 2 Flow formation inside the stilling basin with the discharge of $300\left(\mathrm{~m}^{3} / \mathrm{s}\right)[20,21]$

and the $75 \mathrm{~cm}$ (30 $\mathrm{m}$ in real model) width of basin [20]. For a better performance and the establishment of the hydraulic jump inside the stilling basin for discharge more than the design discharge, the stilling basin walls have been converged with 5, 7.5, 10, and 12.5 angles [20]. The block end of the stilling basin is removed, and three stairs are installed to the level of $1,403 \mathrm{~m}$ of the channel. The walls of the stilling basin were converged, and this stabilized the jump inside the basin. The final characteristics of the stilling basin are presented in Figs. 10 and 11 [20,21].

The design flood of the stilling basin is $500\left(\mathrm{~m}^{3} / \mathrm{s}\right)$ with the return period of 1,000 years. Experiments were done for four discharges as summarized in Table 1. For each discharge, the data were gathered for the values of depth, velocity, and the static pressure in basin section $[20,21]$.

Regarding the thickness of water layer on spillway for preventing viscose effects, the surface tension, the laboratory limitations, and the simulation principles, 1:40 model scale was selected [21]. One of the simulation principles is including Froude number which is the same in laboratory and the dam. A regulated amount of water pumped into model and its discharge measured with rectangular weir set up downstream. For regulating water level, the sluice gate used at the end of canal in model. The length and width of stilling basin in prototype are 43 and $30 \mathrm{~m}$, respectively. The stilling basin model and other parts of it such as the chute constructed of transparent Plexiglas and baffle piers were made of wood covered with oil color. According to project hydrologic studies, the design flood of stilling basin is $500\left(\mathrm{~m}^{3} / \mathrm{s}\right)$ with a return period of 1,000 year [20,21].

\subsection{Measurement in the Model}

In order to measure different parameters of flow in the model, such as the discharge, the depth, the water level, the velocity, the hydrostatic pressures, and the dynamic pressure, different equipment and devices have been used. For each discharge, the values of depth, velocity, and static pressure in basin sections have been measured as defined. When constructing and installing different pieces of equipment including the model itself, we should be very careful since the geometric simulations result in the appropriate systematic similitude between the model and the prototype [20,21]. In the laboratory experiments, devices with specific error percentage have been used as follows [21]:

1. Determination of the levels of different parts by means of a Nivo-Camera with a measurement accuracy of $\pm 0.5 \mathrm{~mm}$ in the model

2. Reading of the water level by means of a point gauge with a measurement accuracy of $\pm 1 \mathrm{~mm}$

3. The velocity measurement uncertainty depending on the flow conditions in different points. In some places where the flow is one-directional, such as the flow in the chute, the velocity has been measured by the pitot tube. In the stilling basin by the micromulline at the depths of 20 and $80 \%$, the velocity has been measured by the micromulline with a measurement accuracy of $\pm 0.05 \mathrm{~m} / \mathrm{s}$.

4. The discharge of model measured by the rectangular sharp crested weir, with a measurement accuracy of $1.3 \%$.

5. Piezometer the simplest device for the pressure measurement used in the laboratory.

6. A pressure gauge used to measure the instant pressures. The measurement error of the dynamic pressure gauge is $\pm 1 \mathrm{~mm}$ water column in the model

In short, it can be said that the rate of uncertainties and the systematic errors is small at the time of measurements and that the highest rate of error results from random errors [21] (Tables 2, 3).

Based on the project conditions, the stilling basin has been designed as a type of USBR II standard model [20]. 
Table 1 Range of discharges $[20,21]$

\begin{tabular}{lllll}
\hline Prototype discharge $\left(\mathrm{m}^{3} / \mathrm{s}\right)$ & 300 & 500 & 830 & 2,270 \\
$\begin{array}{l}\text { Model discharge }(1 / \mathrm{s}) \\
\begin{array}{l}\text { Probability } \\
\text { level }\end{array}\end{array}$ & 30 & 49 & 82 & 224 \\
\hline
\end{tabular}

Table 2 Location of sections in stilling basin [20,21]

\begin{tabular}{lllll}
\hline Section name in model & $Q$ & $P$ & $O$ & $N$ \\
\hline $\begin{array}{c}\text { Distance about spillway } \\
\text { head prototype (m) }\end{array}$ & 315 & 300 & 285 & 277.6 \\
\hline
\end{tabular}

Table 3 Location of bed piezometers in model [20,21]

\begin{tabular}{llllllll}
\hline $\begin{array}{l}\text { No. of piezometers } \\
\text { in stilling basin }\end{array}$ & 1 & 2 & 3 & 4 & 5 & 6 & 7 \\
\hline $\begin{array}{c}\text { Distance about spillway } \\
\text { head prototype (m) }\end{array}$ & 285 & 290 & 295 & 300 & 305 & 310 & 315
\end{tabular}

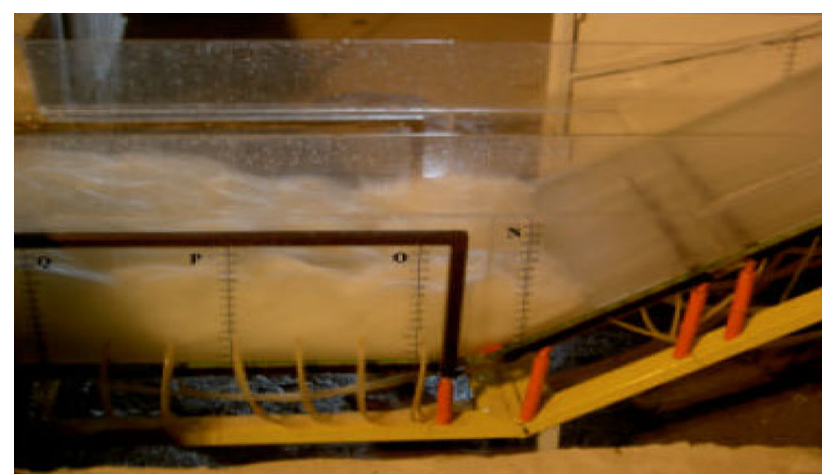

Fig. 3 Stilling basin sections for depth, velocity, and static pressure measuring [20]

To increase the depth ratio and to stabilize the jump in the basin, more preparations are needed, for example, modifications of the baffle piers, the end sill structures, and the effects of the stilling basin walls convergence on the hydraulic jump properties such as the energy dissipation. Experiments have been done for 5, 7.5, 10, and 12.5 degrees of convergence of the stilling basin walls. The converged walls were installed symmetrically in the stilling basin as shown in Fig. 3 [20,21] (Figs. 4, 5, 6, 7, 8).

\section{The Numerical Implementation}

The commercially available computational fluid dynamics (CFDs) program, Flow-3D was used for solving the Reynolds-averaged Navier-Stokes equations. The solver uses finite volume approximations to discrete the computational domain. The pressure and the velocity are coupled implicitly by means of the time-advanced pressures in the

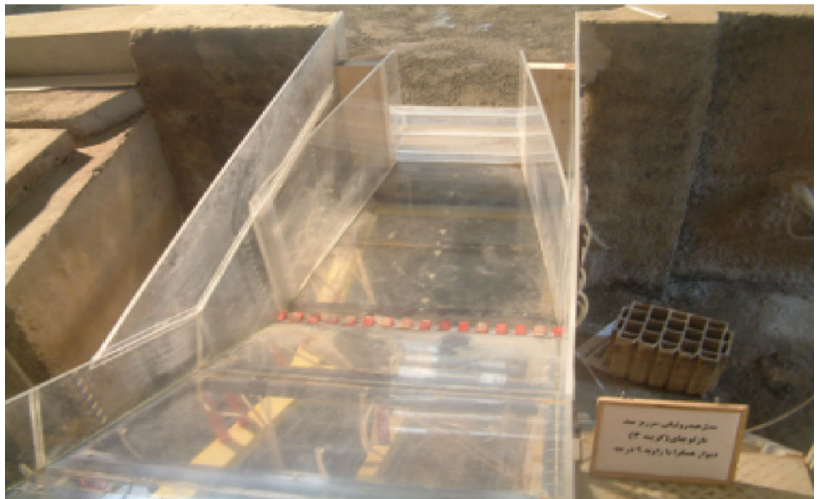

Fig. 4 Final picture of the stilling basin with three steps at the end and convergence walls $[20,21]$

momentum equations and time-advanced velocities in the continuity equations. Turbulence was encountered by both

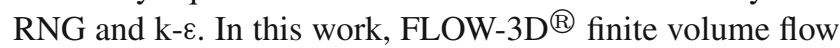
solver is used, which is utilized with the VOF technique for the free surface modeling. In this paper, results of the numerical solution of two turbulent modeling options of the software, RNG and k- $\varepsilon$ models, are used [1].

\subsection{Governing Equations}

The continuity and momentum equations for the fluid flow and the transport equation for the VOF function are as follows: [1,22]

$$
\begin{aligned}
& \frac{V_{f}}{\rho} \frac{\partial \rho}{\partial t}+\frac{1}{\rho} \nabla \cdot\left(\rho \cdot \overline{\mathrm{u}} \cdot A_{\mathrm{f}}\right)=-\frac{\partial V_{f}}{\partial t} \\
& \frac{\partial \bar{u}}{\partial t}+\frac{1}{V_{f}}\left(\bar{u} \cdot A_{f} \cdot \nabla \bar{u}\right)=-\frac{1}{\rho}\left[\nabla P+\nabla \cdot\left(\tau A_{f}\right)\right]+\vec{G} \\
& \frac{\partial F}{\partial t}+\frac{1}{V_{f}} \nabla \cdot\left(F \cdot \bar{u} \cdot A_{f}\right)=-\frac{F}{V_{f}} \frac{\partial V_{f}}{\partial t}
\end{aligned}
$$

where $\rho$ is the fluid density, $\mathrm{v}$ is the fluid velocity, $V_{f}$ is the volume fraction, $A_{f}$ is the area fraction, $P$ is the pressure, $\tau$ is the viscous stress tensor, $G$ is the body accelerations and $F$ is the fluid fraction. The symbol $\mathrm{G}$ in equation (2) denotes the gravity vector, and main equations are given as follows:

$$
\begin{aligned}
& \frac{\partial u}{\partial t}+\frac{1}{V_{F}}\left(u A_{x} \frac{\partial u}{\partial x}+v A_{y} R \frac{\partial u}{\partial y}+w A_{z} \frac{\partial u}{\partial z}\right) \\
& =-\frac{1}{\rho} \frac{\partial P}{\partial x}+G_{x}+f_{x}
\end{aligned}
$$



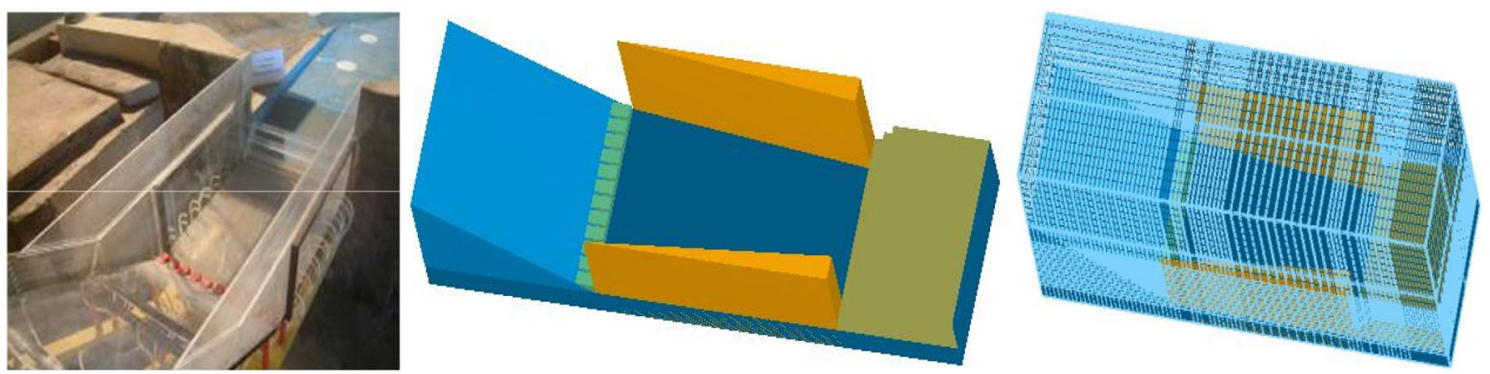

Fig. 5 Computational grid and blocks

Fig. 6 Flow condition in basin for $830\left(\mathrm{~m}^{3} / \mathrm{s}\right)(10$ degree converged wall) with CFD analysis
Fig. 7 Flow condition in basin for $830\left(\mathrm{~m}^{3} / \mathrm{s}\right)(12.5$ degree converged wall)
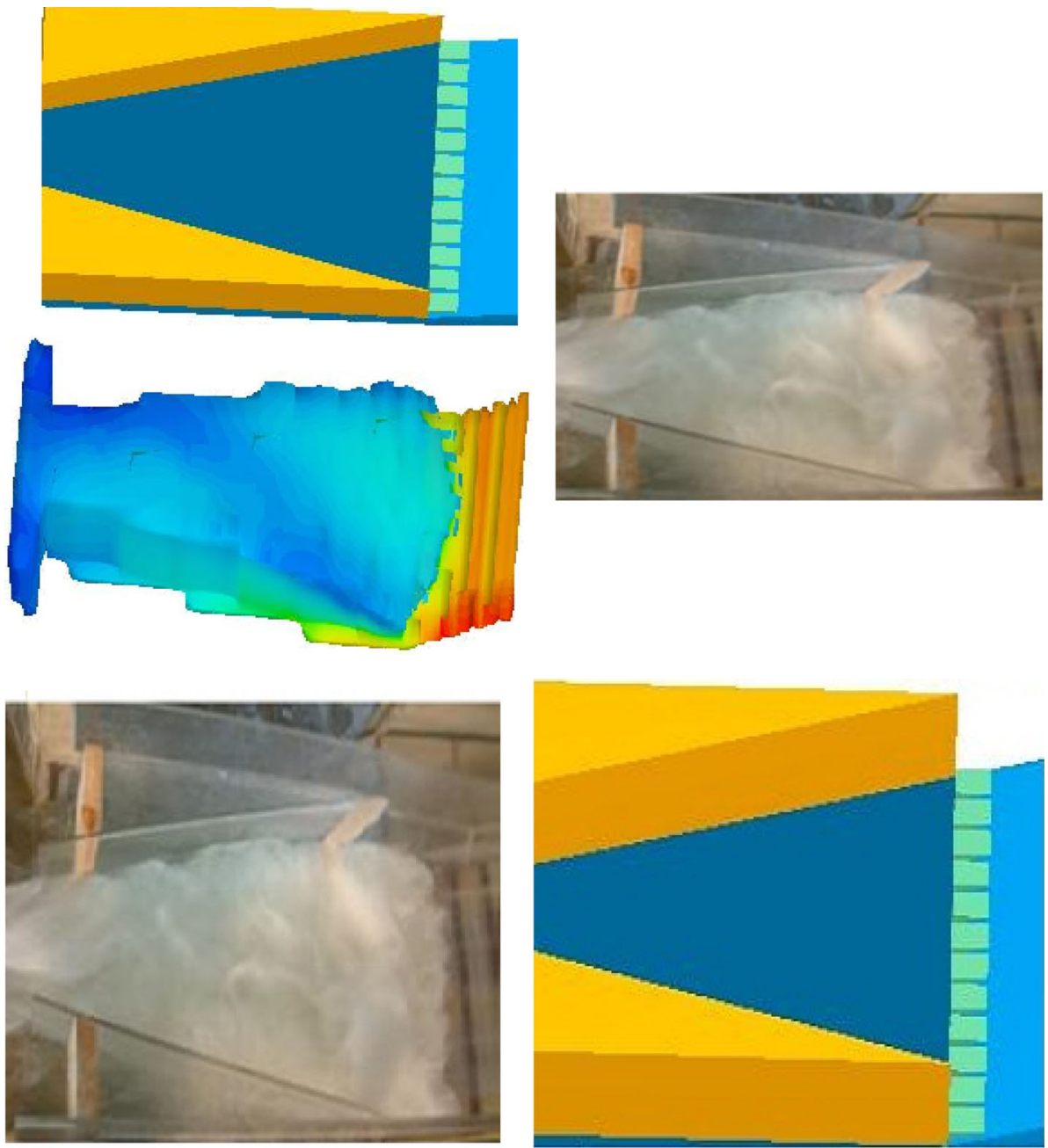

$$
\begin{aligned}
& \frac{\partial v}{\partial t}+\frac{1}{V_{F}}\left(u A_{x} \frac{\partial v}{\partial x}+v A_{y} R \frac{\partial v}{\partial y}+w A_{z} \frac{\partial v}{\partial z}\right) \\
& =-\frac{1}{\rho} \frac{\partial P}{\partial y}+G_{y}+f_{y} \\
& \frac{\partial w}{\partial t}+\frac{1}{V_{F}}\left(u A_{x} \frac{\partial w}{\partial x}+v A_{y} R \frac{\partial w}{\partial y}+w A_{z} \frac{\partial w}{\partial z}\right) \\
& =-\frac{1}{\rho} \frac{\partial P}{\partial z}+G_{z}+f_{z}
\end{aligned}
$$

In these equations, $G_{x}, G_{y}, G_{z}$ are body accelerations, and $f_{x}, f_{y}, f_{z}$ are viscous accelerations [1].
The RANS model includes two transport equations for the turbulent kinetic energy $(k)$ and the rate of turbulence dissipation $(\varepsilon)$ to obtain the Reynolds stress, and the turbulent viscosity $(v t)$ is as follows:

$-\overline{u_{i} u_{j}}=v_{t}\left[\frac{\partial u_{i}}{\partial x_{j}}+\frac{\partial u_{j}}{\partial x_{i}}\right]-\frac{2}{3} \delta_{i j} k$

$v_{t}=c_{\mu} \frac{k^{2}}{\varepsilon}$ 
Fig. 8 Turbulent dissipation for $830\left(\mathrm{~m}^{3} / \mathrm{s}\right)(12.5$ degree converged wall)

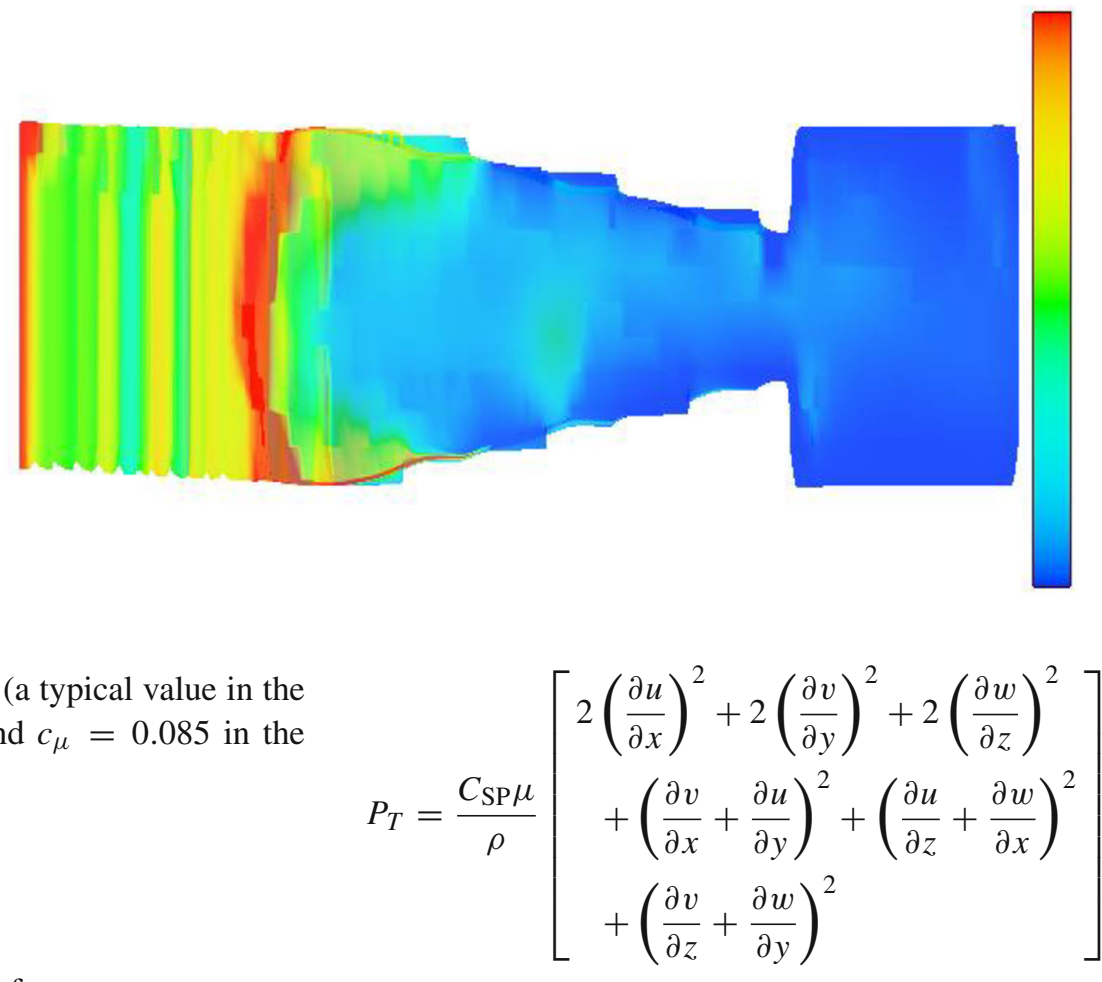

where $c_{\mu}$ is a user-definable constant (a typical value in the standard $\mathrm{k}-\varepsilon$ model is $c_{\mu}=0.09$, and $c_{\mu}=0.085$ in the RNG model) $[1,22]$.

\subsection{Turbulence Transport Models}

A more widely used model consists of two transport equations for the turbulent kinetic energy $k_{T}$ and its dissipation $\varepsilon_{T}$, the so-called $\mathrm{k}-\varepsilon$ model $[3,23]$. The $\mathrm{k}-\varepsilon$ model has been shown to provide reasonable approximations to many types of flows [1]. An additional transport equation must be solved for the turbulent dissipation, $\varepsilon_{T}$. The turbulence kinetic energy, $k$, and its rate of dissipation, $\varepsilon$, are obtained from the following transport equations:

$$
\begin{aligned}
& \frac{\partial k}{\partial t}+\frac{1}{V_{F}}\left\{u A_{x} \frac{\partial k}{\partial x}+v A_{y} \frac{\partial k}{\partial y}+w A_{z} \frac{\partial k}{\partial z}\right\} \\
& =P_{T}+G+D_{\text {iff }}-\varepsilon \\
& \frac{\partial \varepsilon}{\partial t}+\frac{1}{V_{F}}\left\{u A_{x} \frac{\partial \varepsilon}{\partial x}+v A_{y} \frac{\partial \varepsilon}{\partial y}+w A_{z} \frac{\partial \varepsilon}{\partial z}\right\} \\
& =\frac{c_{1 \varepsilon} \cdot \varepsilon}{k}\left(P_{T}+C_{3 \varepsilon} \cdot G\right)+D_{\text {Dif }}-C_{2 \varepsilon} \cdot \frac{\varepsilon^{2}}{k}
\end{aligned}
$$

where $P_{T}$ is the shear production, $G$ is the buoyancy production, $D_{\text {iff }}$ and $D_{\text {Dif }}$ represent diffusion and $C 1 \varepsilon, C 2 \varepsilon, C 3 \varepsilon$ are constants. In standard $k-\varepsilon$ model $C 1 \varepsilon=1.44$ and $C 2 \varepsilon=$ 1.92. $G$ is the buoyancy production term and described as below:

$G=\frac{C_{P} \mu}{\rho^{3}}\left[\frac{\partial \rho}{\partial x} \frac{\partial P}{\partial x}+\frac{\partial \rho}{\partial y} \frac{\partial P}{\partial y}+\frac{\partial \rho}{\partial z} \frac{\partial P}{\partial z}\right]$

where $C$ has a default value of 0.0 , unless the problem is thermally buoyant, in which case it takes on the value of 2.5 [1]. Where $P_{T}$ in Cartesian coordinates is:
Here, $C_{\mathrm{SP}}$ is the shear production coefficient $[1,22]$.

Another turbulence model is based on renormalization group (RNG) methods [1,9] and [23]. This approach applies statistical methods to the derivation of the averaged equations for turbulence quantities such as turbulent kinetic energy and its dissipation rate. The RNG $\mathrm{k}-\varepsilon$ model was derived using a rigorous statistical technique (called renormalization group theory). It is similar in form to the standard $\mathrm{k}-\varepsilon$ model, but includes the following refinements [24]:

- The RNG model has an additional term in its $\varepsilon$ equation that significantly improves the accuracy for rapidly strained flows.

- The effect of swirl on turbulence is included in the RNG model, enhancing accuracy for swirling flows.

- The RNG theory provides an analytical formula for turbulent Prandtl numbers, while the standard k- $\varepsilon$ model uses user-specified, constant values.

- While the standard $\mathrm{k}-\varepsilon$ model is a high-Reynolds number model, the RNG theory provides an analytically derived differential formula for effective viscosity that accounts for low-Reynolds number effects. Effective use of this feature does, however, depend on an appropriate treatment of the near-wall region.

The RNG-based models rely less on empirical constants while setting a framework for the derivation of a range of models at different scales. The RNG model uses equations similar to the equations for the $\mathrm{k}-\varepsilon$ model. Equation constants that are found empirically in the standard $\mathrm{k}-\varepsilon$ model are derived explicitly in the RNG model. Generally, the 


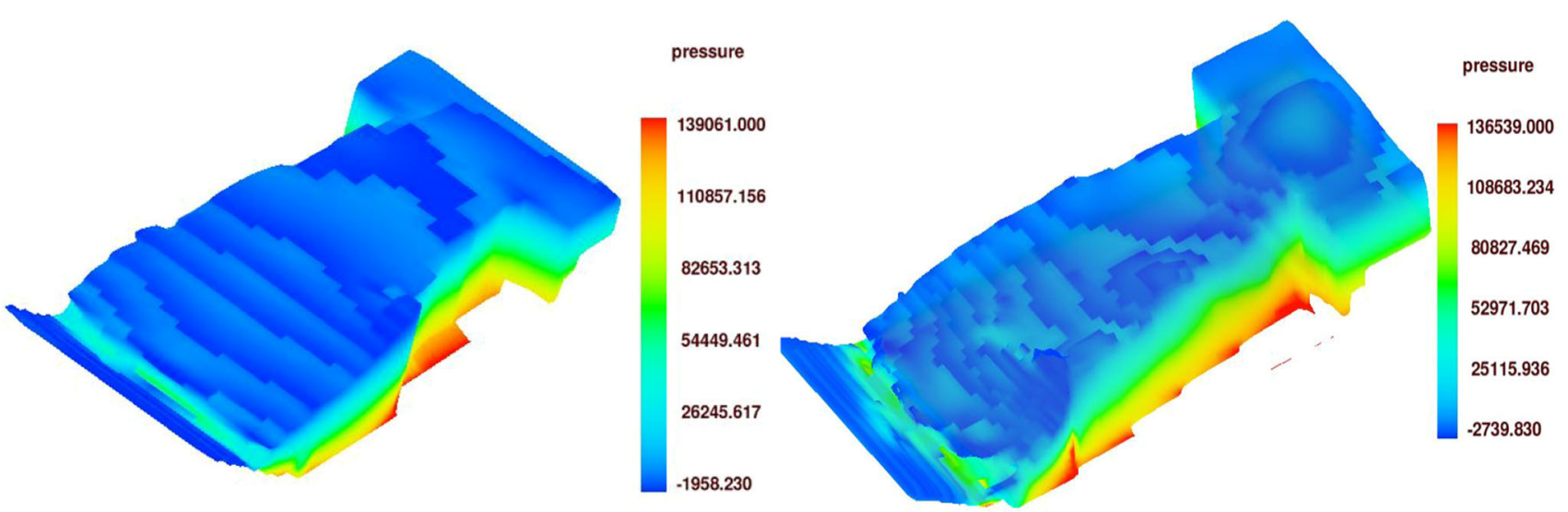

Convergence walls: $10^{\circ}$

Fig. 9 Pressure distribution for discharge $=300\left(\mathrm{~m}^{3} / \mathrm{s}\right)$, left $\mathrm{k}-\varepsilon$ model, right $\mathrm{RNG}$ model

Fig. 10 Comparison of numerical and physical model of the pressure for discharge $=300$ $\left(\mathrm{m}^{3} / \mathrm{s}\right)$

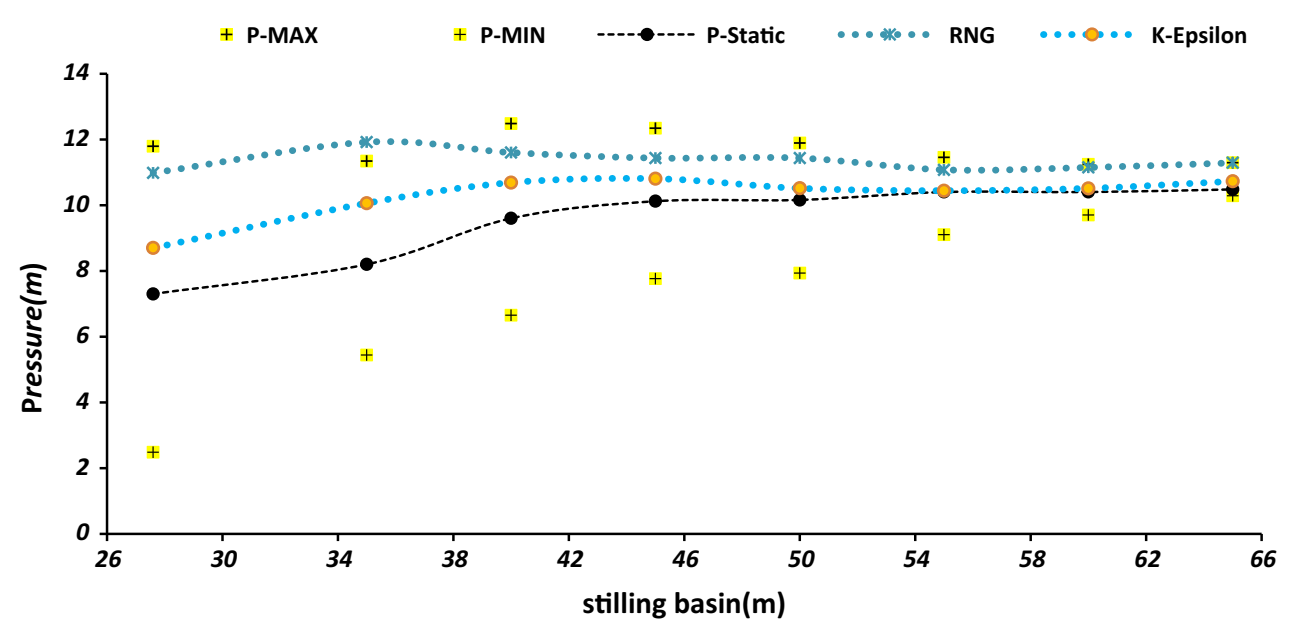

RNG model has wider applicability than the standard $\mathrm{k}-\varepsilon$ model. In particular, the RNG model is known to more accurately describe low-intensity turbulence flows and flows having strong shear regions. In RNG model, $C 1 \varepsilon=1.42$ and $C 2 \varepsilon=1.68[1,25]$.

\subsection{The Free Surface Trace Equation}

Free surface boundaries and the fluid interfaces are treated by means of the volume-of-fluid (VOF) technique [22].VOF is based on the definition of a function $F$ (volume fraction), whose value at any grid point is 1 if occupied by the fluid and 0 if it is not fluid. $F$ is, therefore, a continuous function bounded by 0 and 1 , and it is governed by the following convection transport equation:

$$
\frac{\partial F}{\partial t}+\frac{\partial\left(F \cdot u_{j}\right)}{\partial x_{j}}=0
$$

The VOF technique is both accurate and effective, since it only requires the computation and storage of one additional variable $(F)[3,22]$ and [1].

\subsection{Air Entrainment Relations}

Air entrainment at a liquid surface is based on the idea that turbulent eddies raise small liquid elements above a free surface that may trap air and carry it back into the body of the liquid. The extent to which liquid elements can be lifted above a free surface depends on whether or not the intensity of the turbulence is enough to overcome the surface stabilizing forces of gravity and surface tension. Turbulence transport models characterize turbulence by a specific turbulent kinetic energy $Q$ and a dissipation function, $D[25,26]$ and [27]. A characteristic size of turbulence eddies is then given by $L_{t}=\operatorname{cnu}(3 / 2)^{1 / 2} Q^{3 / 2} D$. We use this scale to characterize surface disturbances. The disturbance kinetic energy per 
Fig. 11 Comparison of numerical and physical model of the pressure for discharge $=500$ $\left(\mathrm{m}^{3} / \mathrm{s}\right)$

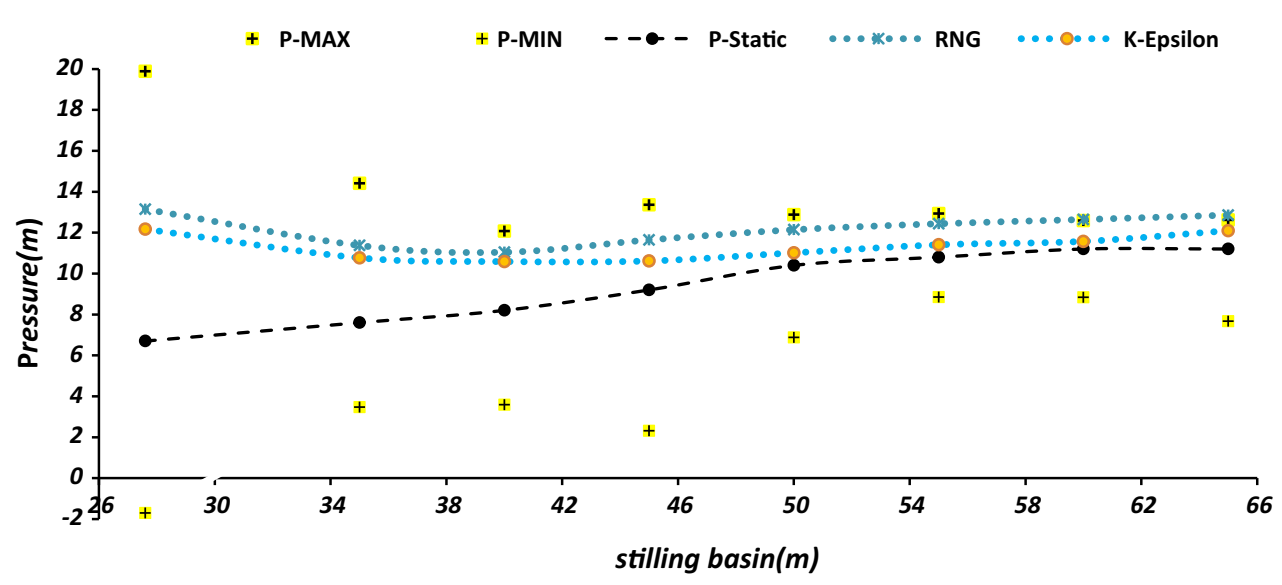

unit volume (i.e., pressure) associated with a fluid element raised to a height $L t$ and with surface tension energy based on a curvature is $P_{d}=\rho g_{n} L_{t}+\frac{\sigma}{L_{t}}$ of $L_{t}$, where $\rho$ is the liquid density, $\sigma$ is coefficient of surface tension, and $g_{n}$ is the component of gravity normal to the free surface. For air entrainment to occur, the turbulent kinetic energy per unit volume, $P_{t}=\rho Q$, must be larger than $P_{d}$, i.e., the turbulent disturbances must be large enough to overcome the surface stabilizing forces. The volume of air entrained per unit time, $\delta V$, should be proportional to the surface area, $a_{s}$, and the height of the disturbances above the mean [25,26] and [27].

Surface level $\delta V=C_{a i r} A_{s} \sqrt{\left(2\left(P_{t}-P_{d}\right) / \rho\right.}$ all together we write where $C_{\text {air }}$ is a coefficient of proportionality. If $P_{t}$ is less than $P_{d}$, then $\delta V$ is zero. The value of $C_{\text {air }}$ is expected to be less that unity, because only a portion of the raised disturbance volume is occupied by air. A good first guess is $C_{\text {air }}=0.5$, i.e., assume on average that air will be trapped over about half the surface area [25,26] and [27]. For the numerical solution, the laboratory model of the stilling basin of the Nazloo Dam was used. To investigate the performance of spillway and the stilling basin, the hydraulic model of flood discharge was used on the basis of the similarity of dimensionless Froude numbers with the scale 1:40 in the water research center [11,21].

Plexiglas was the material of the bottom and the walls of spillway model and the stilling basin [20,21]. By this model, the main variables of flow such as the depth, the velocity, and the pressure were measured. To simulate the stilling basin, a 3-D network in the real scale was used. Given the use of software for modeling barriers, and the basin blocks, a network should be used with adequate considerations.

We first had to become sure of the process of our calculation. To this end, several models relating to the previous research were tested, and good results were derived. At the next step, we had to become sure of our dimensions of mesh. Therefore, 24 models were run for the determination of the best mesh dimensions. The following table presents the results. If the number of cells is more than 500,000, the results obtained from the numerical software are consistent with the laboratory results. Given the solution time for each model, and given the file size of each model, 864,000 cells were selected. Moreover, results will not be very different for cells greater than the above number. A rectangular cubic network is used, and the dimensions of each cell in this network are similar, each being $0.10 \mathrm{~m}$. The laboratory data are used to compare the flow parameters in the stilling basin, such as the water level, the flow velocity, and the basin pressure bottom. In Figs. 9, 10, 11, 12, 13, 14, 15, 16, 17, 18, 19, 20, $21,22,23,24$, and 25 , the calculated values of numerical solution are compared with the measured values [20,21].In this paper, we studied the numerical model of jump on 6 conditions. One of the conditions was the stilling basin with the parallel wall connected with the mild slope at the end of the basin and the baffles at the beginning of slope being connected with the downstream. Another condition was the stilling basin with the parallel wall being linked with three stairs at the end of basin and the barriers at the beginning of the stair being connected with the downstream. The jump inside the stilling basin was studied with convergence wall and degrees, $5^{\circ}, 7.5^{\circ}, 10^{\circ}$, and $12.5^{\circ}$, and three stairs are linked to the downstream.

In case of good performance of the basin, the flow goes out in an under-critical form after the energy is dissipated by the hydraulic jump. To simulate the super-critical flow and the entrance of this flow into the basin, $30 \mathrm{~m}$ of the end of chute is simulated in basin model.

\subsection{Boundary Conditions}

Because the flow domain is defined as a hexahedral in the Cartesian coordinates, there are six different boundaries on the mesh, plus the obstacle surface. The boundaries on the mesh and their coordinate directions were set as follows (Table 4):

Given the air entrance to the flow in the hydraulic jump and its effect on the energy loss in the basin, the software air 


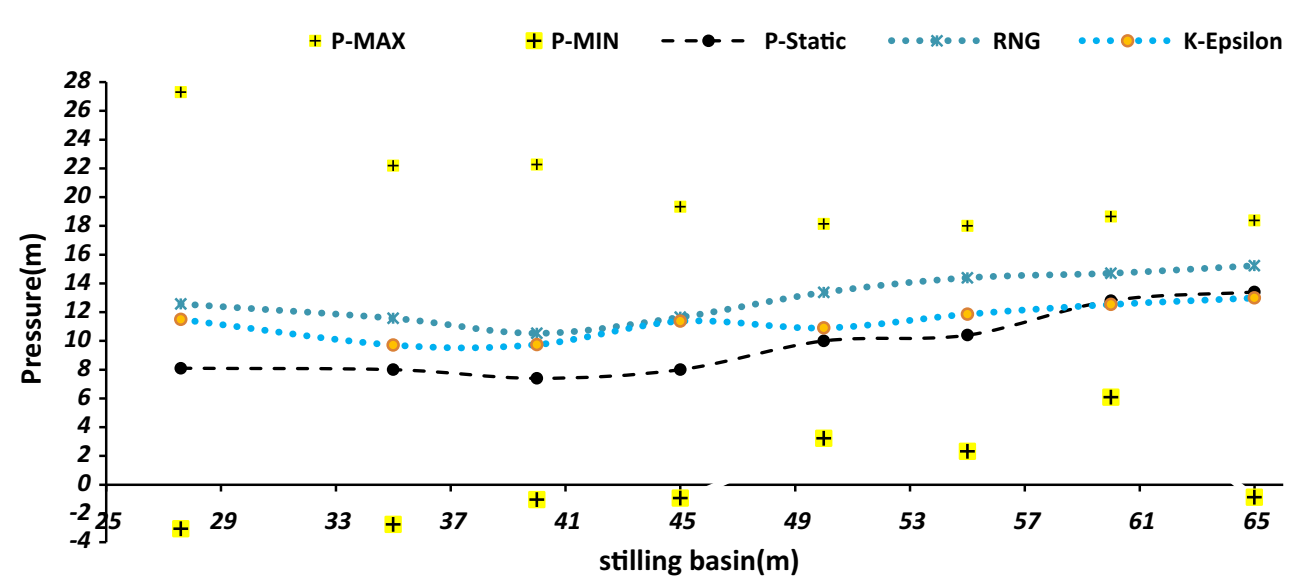

Fig. 12 Comparison of numerical and physical model of the pressure for discharge $=830\left(\mathrm{~m}^{3} / \mathrm{s}\right)$

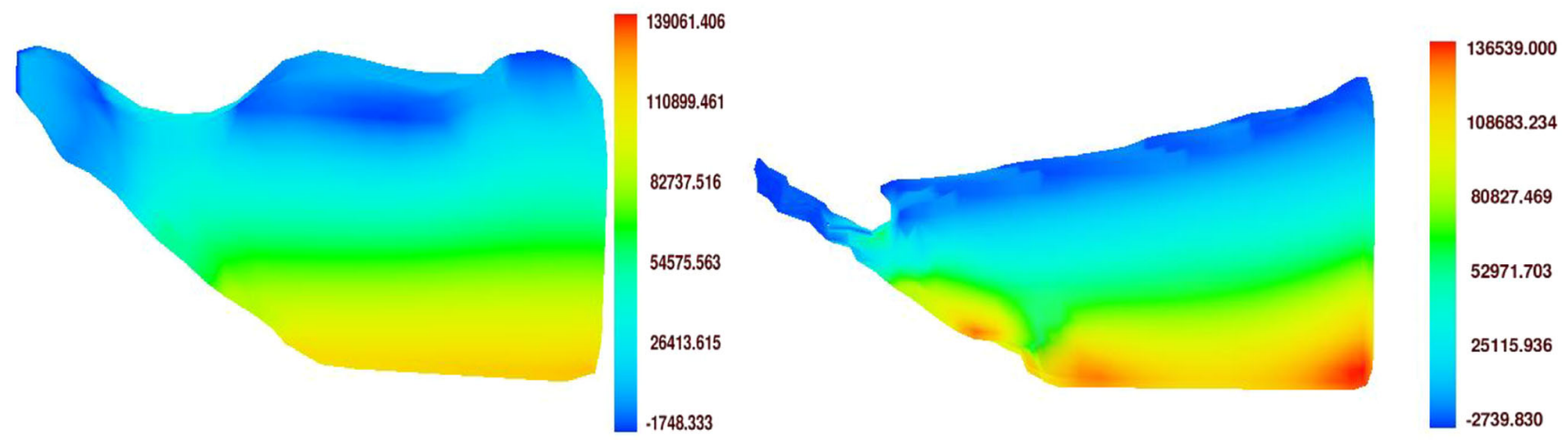

Fig. 13 Pressure distribution in the inlet of the stilling basin for discharge $=300\left(\mathrm{~m}^{3} / \mathrm{s}\right)$, left $\mathrm{k}-\varepsilon$, right $\mathrm{RNG}$ model

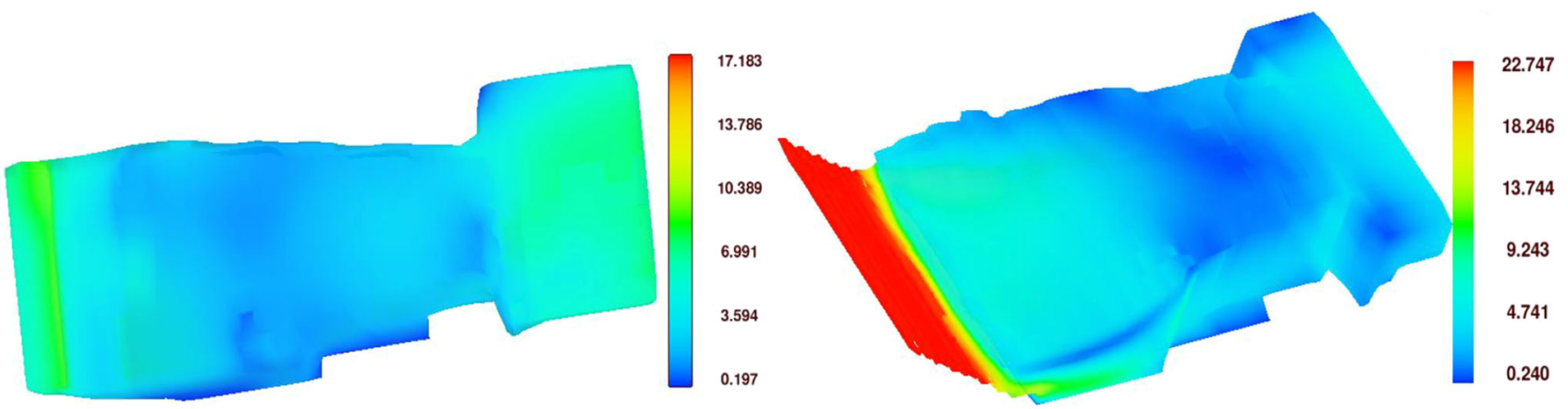

\section{Convergence Walls: $10^{\circ}$}

Fig. 14 Velocity distribution for discharge $=300\left(\mathrm{~m}^{3} / \mathrm{s}\right)$, left $\mathrm{k}-\varepsilon$, right $\mathrm{RNG}$ model

model is used. The existing laboratory data are used to compare the flow parameters in the stilling basin, including the water level, the flow velocity, and the basin pressure bottom. The basin has been divided into a network for the sake of its length, width, and height. The results are presented by two turbulence $\mathrm{k}-\varepsilon$, RNG models.

\section{Results}

4.1 The pressure in the stilling basin

Figures 9, 10, 11, and 12 show the pressure values inside the basin. In these figures, one can see the hydrostatic pressure 


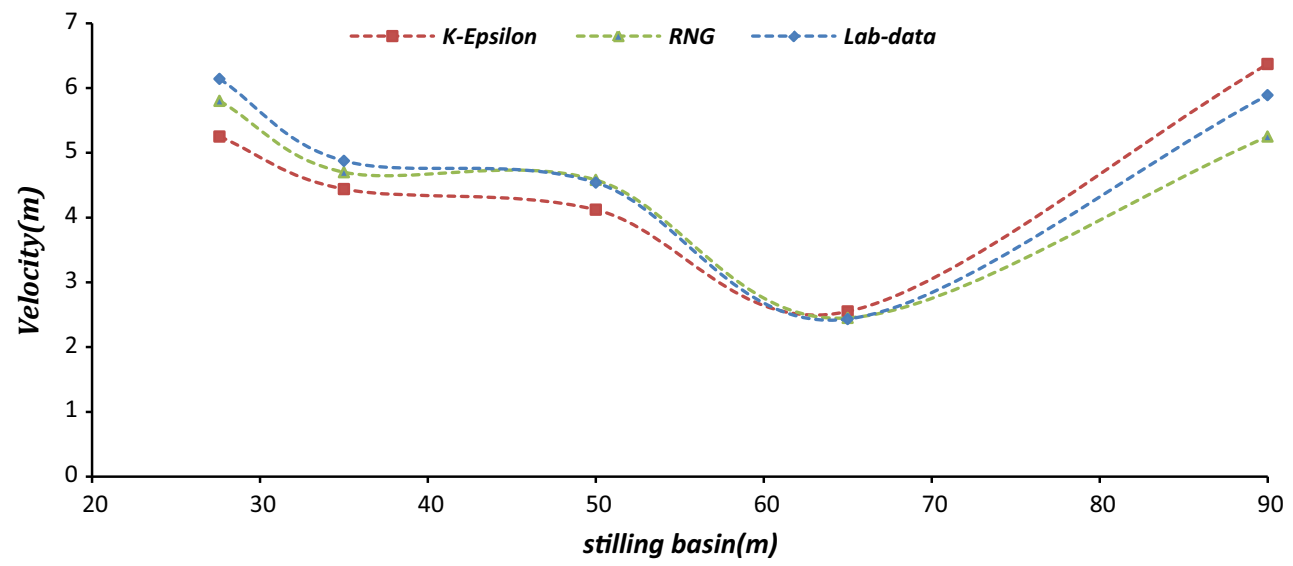

Fig. 15 Comparison of numerical model and physical model velocity for discharge $=300\left(\mathrm{~m}^{3} / \mathrm{s}\right)$

Fig. 16 Velocity magnitudes for discharge $=300\left(\mathrm{~m}^{3} / \mathrm{s}\right)$

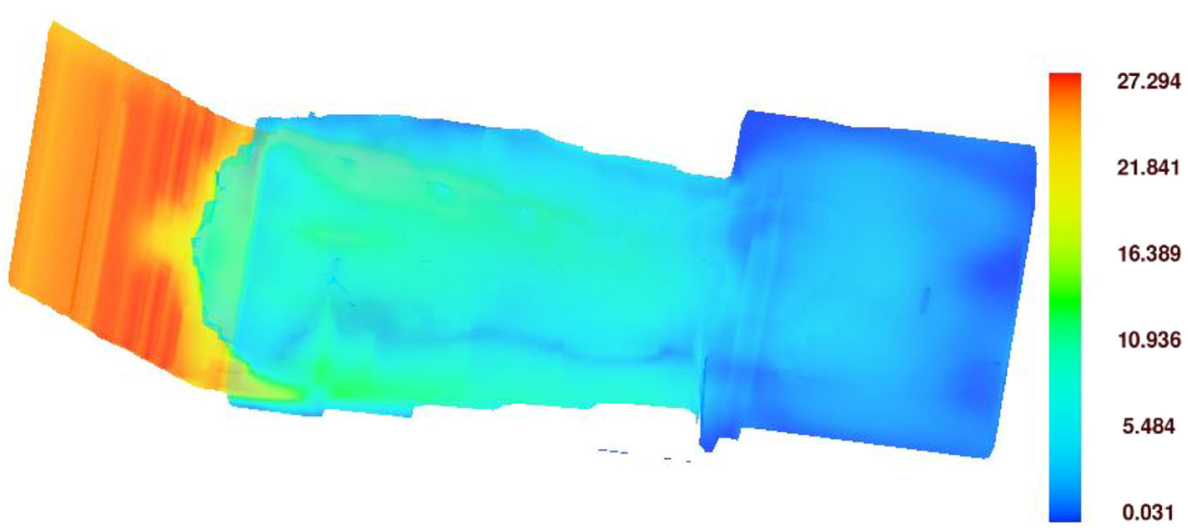

Convergence Walls: $10^{\circ}$

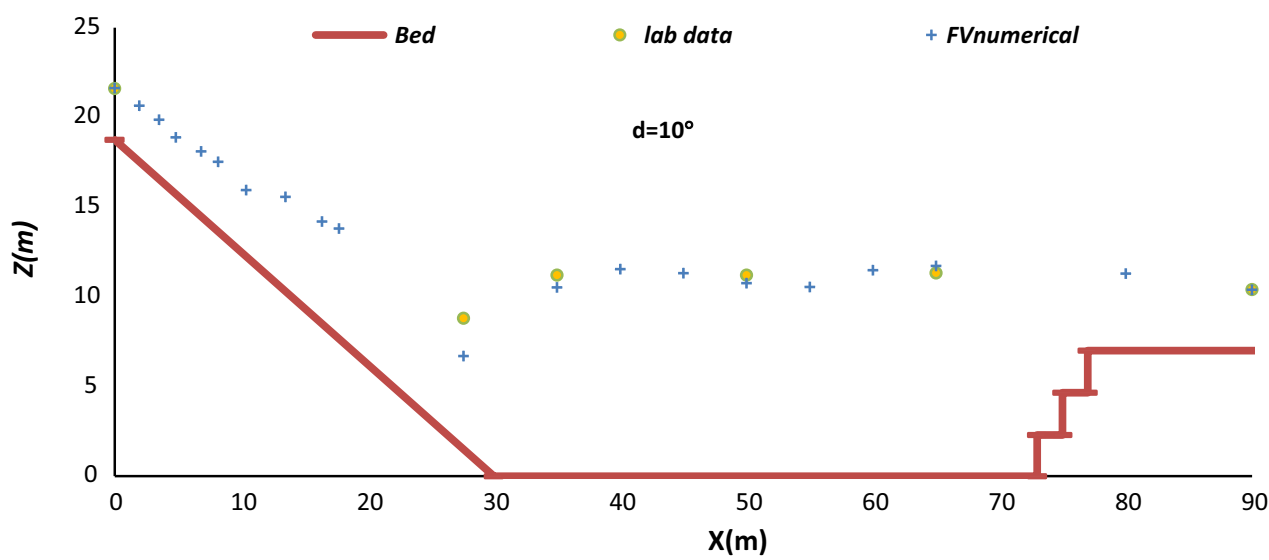

Fig. 17 Water surface profile for $Q=300\left(\mathrm{~m}^{3} / \mathrm{s}\right)$ by k- $\varepsilon$ method the contact of flow with the obstacles, the pressure increases at the beginning and end of the basin. Based on the results of the two methods $\mathrm{k}-\varepsilon$ and RNG, the bottom pressure profiles show good results, with the RNG model being a bit better $[20,26]$.

In Fig. 13, the pressure is presented around the beginning barriers of the basin as a 3-D model for the flood discharge $=300\left(\mathrm{~m}^{3} / \mathrm{s}\right)$, and $12.5^{\circ}$. As shown in this figure, the the hydrostatic distribution. The bottom pressure profiles accordance with the hydrostatic pressure distribution, due to 
Fig. 18 Water surface profile for $Q=300\left(\mathrm{~m}^{3} / \mathrm{s}\right)$ by RNG method

Fig. 19 Numerical solutions for 5 degree convergence walls
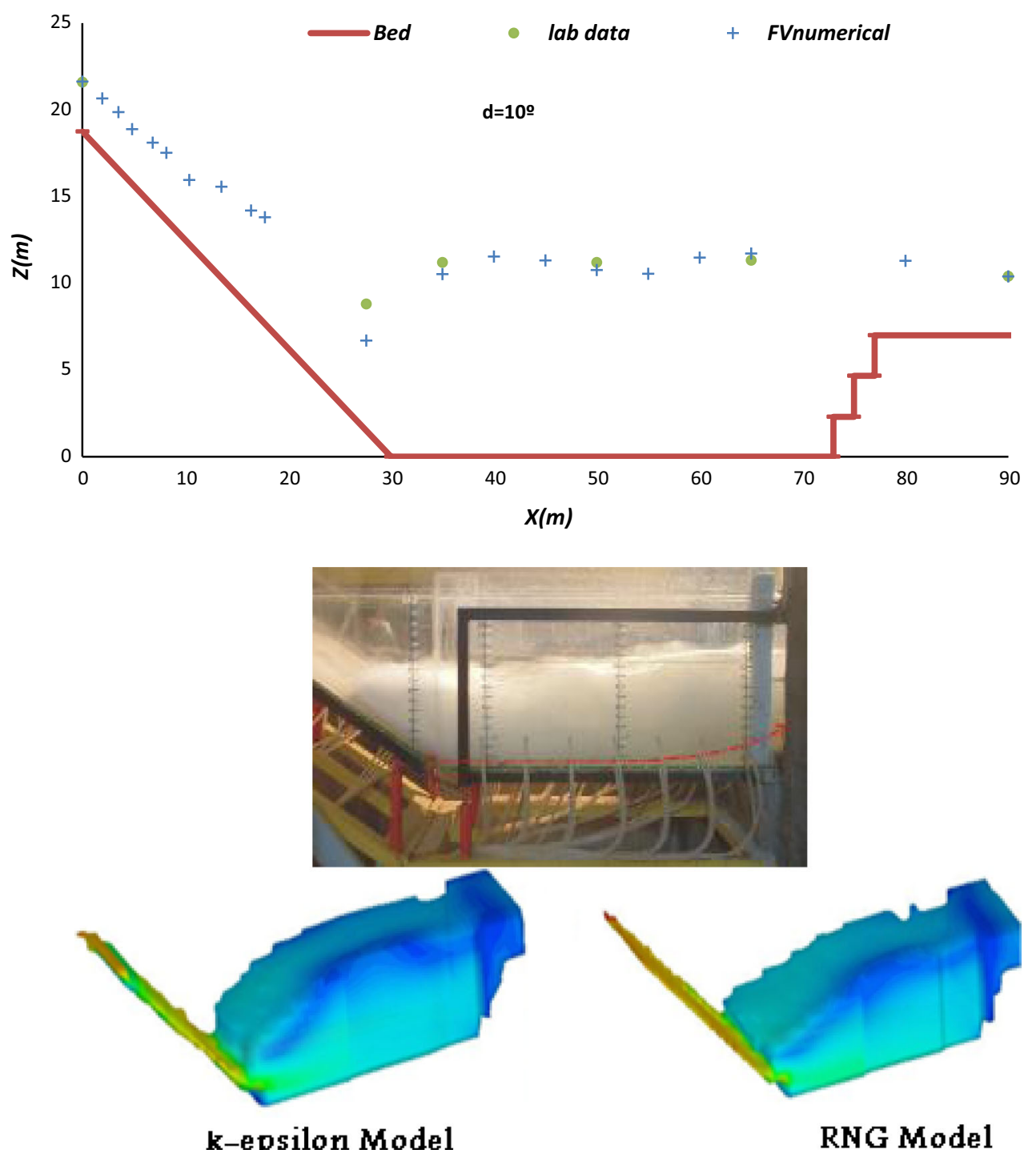

pressure in front of these barriers is a high value and the reason is the contact of the flow with these barriers. At the beginning of the basin, non-hydrostatic distribution of the pressure does exist, as it is quite evident in both methods of $\mathrm{k}-\varepsilon$ and $\mathrm{RNG}$.

\subsection{The Velocity Distribution}

Figures 14, 15, and 16 show the horizontal velocity values in the basin. It seems that the horizontal velocity inside the basin and near the water surface has negative values due to the rotation of the flow in this section, as it is clear in the horizontal velocity distribution of the flow in the calculated stilling basin. In addition, the horizontal velocity distribution of the flow near the bottom is consistent with laboratory values. Moreover, as Figs. 16, 17, and 18 show, the velocity increases at the end of the basin.
The RNG model seems to produce slightly better results than the k-epsilon model.

\subsection{The Water Surface Profile}

Figures 17 and 18 show the water surface profile for the discharge of $300\left(\mathrm{~m}^{3} / \mathrm{s}\right)$. In the basin, as shown in the figure, the numerical solution predicted good results, compared with the laboratory measurements. The water level inside the basin showed good consistency with the laboratory values. In the initial region of the jump, due to the high turbulence of the flow, the calculated values are different from the measured values, but this difference at the end of jump is decreased considerably due to the reduction in turbulence. Both turbulence models $k-\varepsilon$ and RNG showed exact results for the calculation of the profile of the water level in discharge $300\left(\mathrm{~m}^{3} / \mathrm{s}\right)$. The agreement is remarkable for a field situation. 
Fig. 20 Back flows of walls in different angles for $500\left(\mathrm{~m}^{3} / \mathrm{s}\right)$, a 5 Degree convergence walls.

b 7.5 Degree convergence walls,

c 10 degree convergence walls,

d 12.5 degree convergence walls (a)
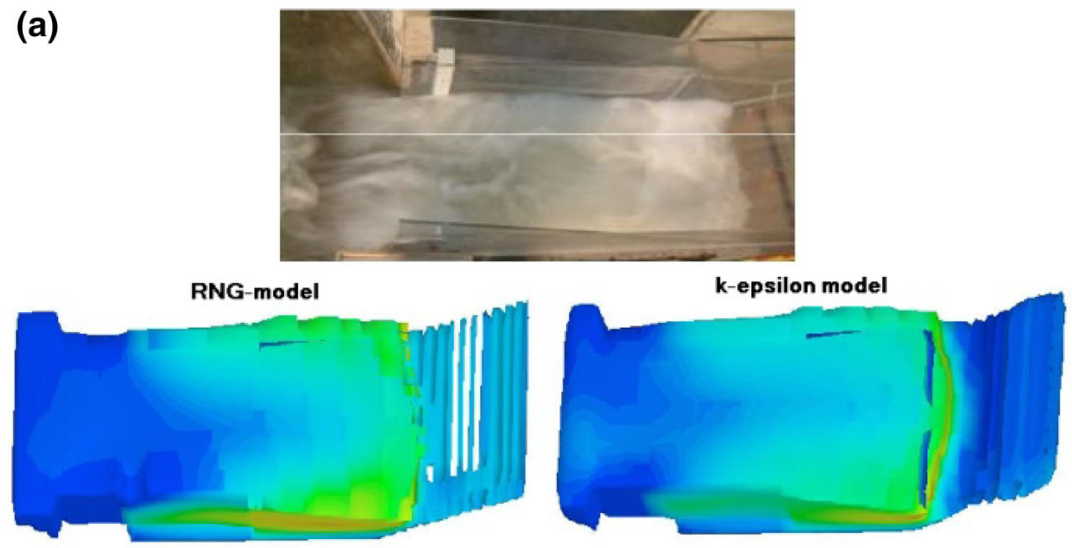

(b)

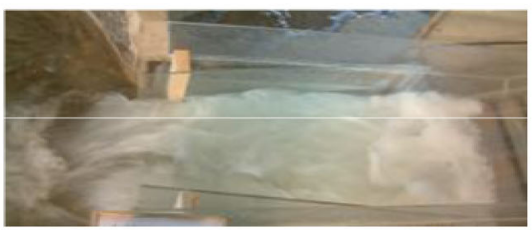

RNG-model

k-epsilon model
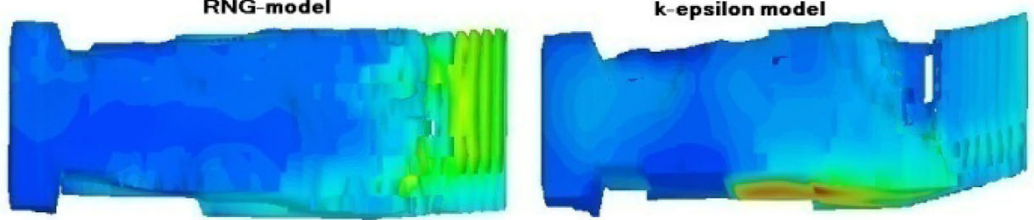

(c)

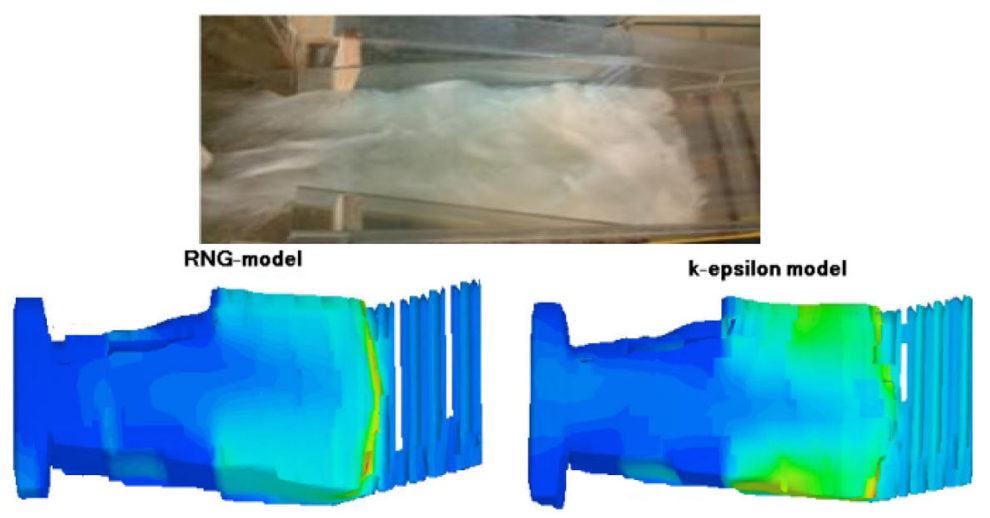

(d)
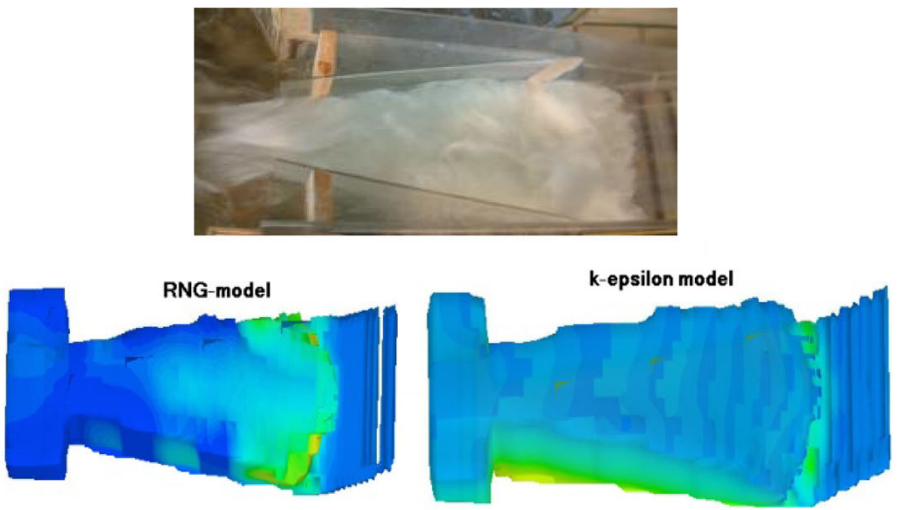

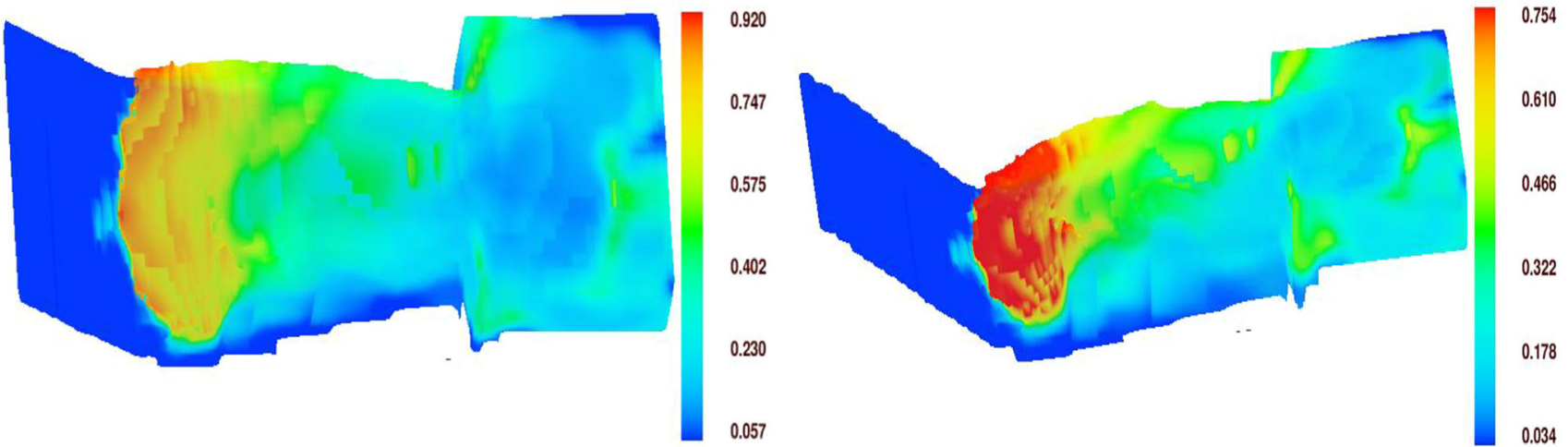

Fig. 21 Air volume values for $Q=300\left(\mathrm{~m}^{3} / \mathrm{s}\right)$ in different states of basin, left $\mathrm{k}-\varepsilon$, right $\mathrm{RNG}$ models
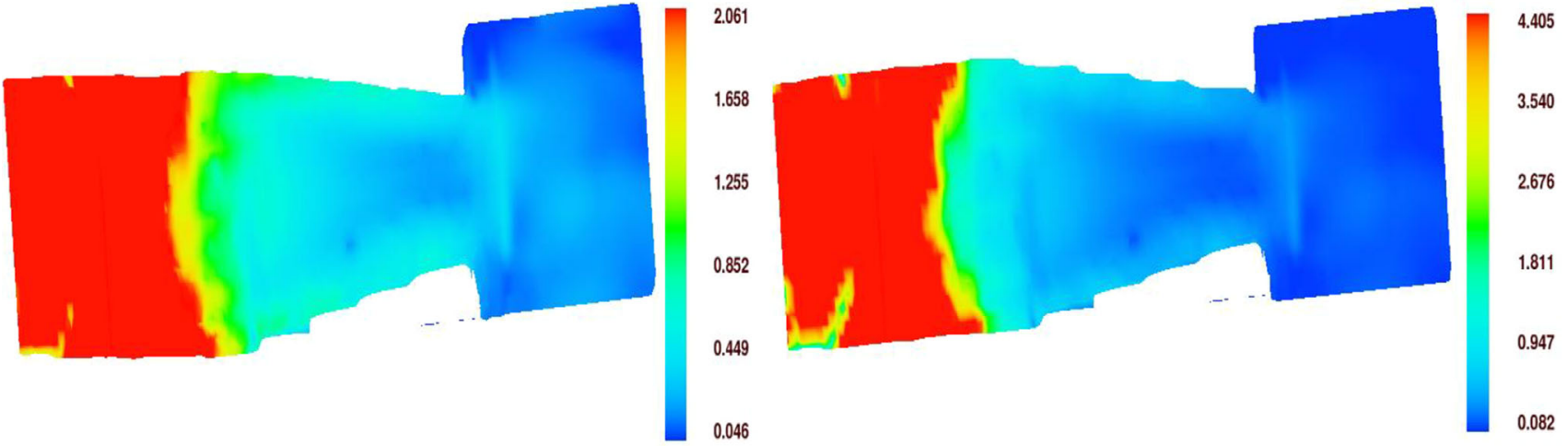

Fig. 22 Froude number distributions for $Q=300\left(\mathrm{~m}^{3} / \mathrm{s}\right)$, left $\mathrm{k}-\varepsilon$, right $\mathrm{RNG}$

Fig. 23 Froude number inside the basin for $Q=300\left(\mathrm{~m}^{3} / \mathrm{s}\right)$, degree of convergence wall $=5^{\circ}$

\subsection{Fraction of Entrained Air}

Figure 21 shows the air inside the flow. As shown in this figure, the inflow to the basis is self-aerated. At the jump toe, more air enters into the flow, and the farther we go from the jump toe, the less air we see within the flow, as it is evident in models $\mathrm{k}-\varepsilon$ and $\mathrm{RNG}$

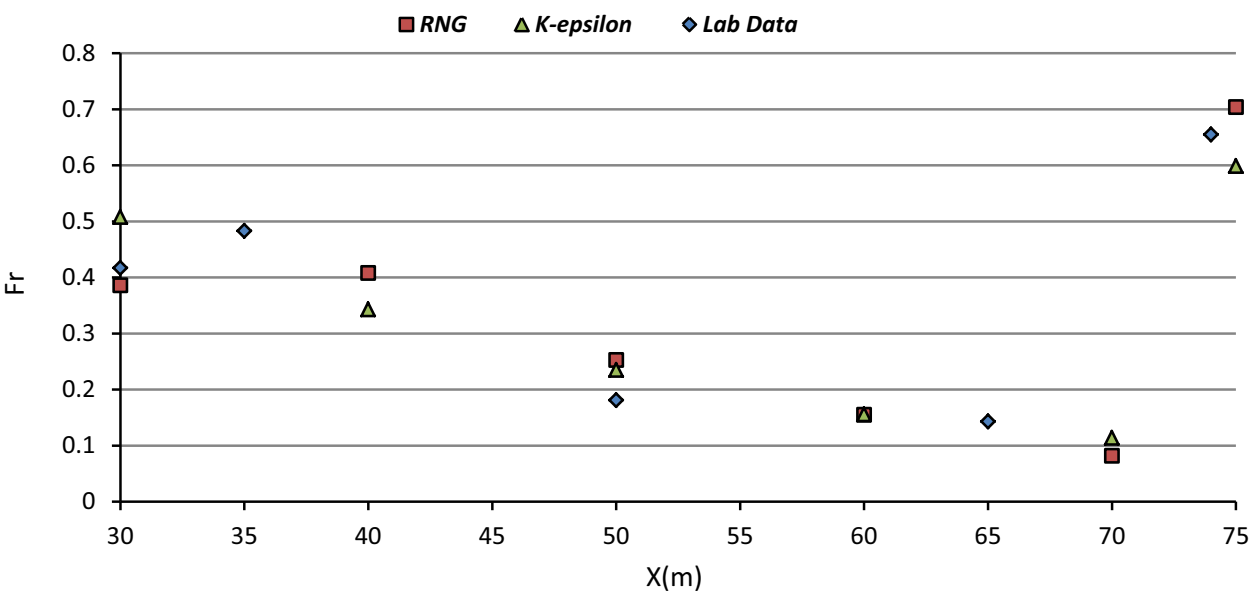

\subsection{Froude Number Values}

Figures 22 and 23 show the Froude values in the flow. As expected, Froude numbers at the beginning of basin have less value than the chute. Inside the basin, the subcritical flow is created, and in the exit basin, the Froude number increases as the velocity increases, as the figures show. 


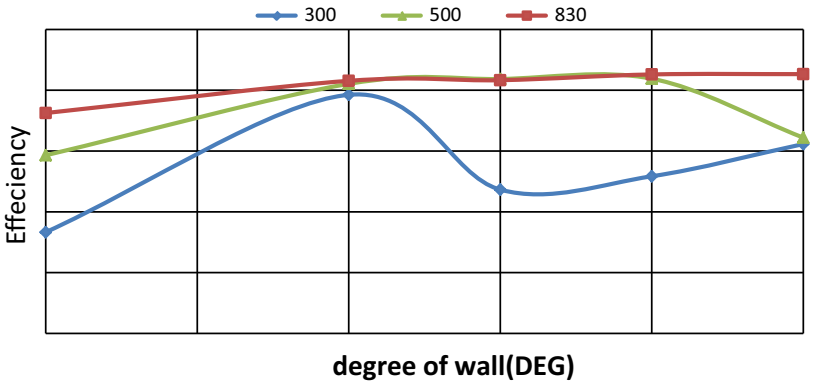

Fig. 24 Hydraulic jump efficiency in different angles of the stilling basin $[20,21]$

Based on the figures, we can say that the RNG method showed better results compared with the k-epsilon method. The consistency of the laboratory results and numerical models are interesting in various aspects.

\subsection{The Efficiency of the Hydraulic Jump}

The results show that in all the discharges, the hydraulic jump performance in the basin with convergent wall is much better than the parallel form. With the increase of the discharge, this difference becomes evident. Increasing the convergence degree from $5^{\circ}$ to $12.5^{\circ}$ does not have considerable effects on the efficiency increase [20,21]. Given the fixed cost of the walls, the best convergence degree for the dissipation energy is $5^{\circ}[20,21]$. Efficiency of dissipation energy in the hydraulic jump is computed with $[20,21]$ :

$$
\begin{aligned}
& E_{1}=y_{1}+\frac{v_{1}^{2}}{2 \mathrm{~g}} \\
& E_{2}=y_{2}+\frac{v_{2}^{2}}{2 \mathrm{~g}} \\
& \eta=\frac{\left(E_{2}-E_{1}\right)}{E_{1}} \times 100
\end{aligned}
$$

where $E$ is the specific energy, $V$ the velocity, and $\eta$ the efficiency of dissipation energy

\section{Conclusion}

The objective of this study was to evaluate the hydraulic jump in the convergence stilling basin USBR II. This task was done by means of Flow-3D finite volume numerical model. The numerical modeling shows that Flow-3D predicted that the flow pattern agrees with the general flow profile in the stilling basin, and this numerical software can predict the hydraulic jump. Flow parameters in the hydraulic jump were used for laboratory data, and the results of numerical simulation were compared by two turbulence models, the $\mathrm{k}-\varepsilon$ and RNG methods. The comparison of the computed results of the hydraulic jump in the stilling basin with the experimental measurements shows that in all the discharges, the hydraulic jump in the basin with converged walls is better than the parallel walls. The comparison of the results showed that the numerical solution can well predict the existing parameters in the hydraulic jump, such as the velocity,
Fig. 25 Comparison of numerical and physical model the hydraulic jump efficiency for $Q=300\left(\mathrm{~m}^{3} / \mathrm{s}\right)$
Table 4 Boundary conditions of the stilling basin of simulated numerical model

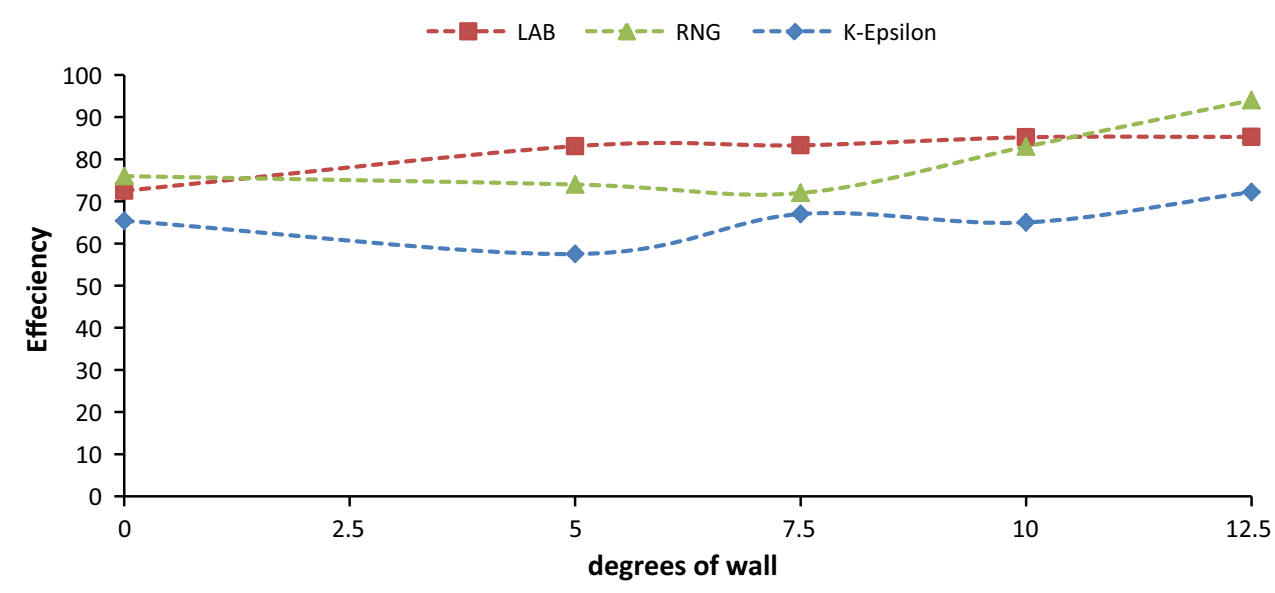

\begin{tabular}{lllll}
\hline $\begin{array}{l}\text { Bottom of } \\
\text { model }(\mathrm{Zmin})\end{array}$ & Top of model (Zmax) & Sidewalls $y$ & Left $x$ & Right $x$ \\
\hline pressure & free slip/symmetry & free slip/symmetry & $\begin{array}{l}\text { local stagnation pressure } \\
\text { based on total head } \\
\text { with a hydrostatic } \\
\text { pressure distribution }\end{array}$ & continuative \\
& & & & \\
& & &
\end{tabular}


the pressure, Froude numbers, and the air entrance. In this numerical solution, the RNG turbulence model presented better results. FLOW-3D ${ }^{\circledR}$ results show that the RNG turbulence closure, when combined with the VOF surface tracking method, can accurately predict separation zones as well as 3-D patterns of the fluid motion. The agreement is remarkable for a field situation. Results are satisfactorily accurate, as they confirm the experimental findings from the physical models.

Open Access This article is distributed under the terms of the Creative Commons Attribution License which permits any use, distribution, and reproduction in any medium, provided the original author(s) and the source are credited.

\section{References}

1. FLOW-3D User Manual 9.4. Volume 1. November 13 (2009)

2. Hou, F.; Ma, Y.; Prinos, P.: Numerical calculation of submerged hydraulic jump. J. Hydraul. Res. 39(5), 1-11 (2002)

3. Thandaveswara, B.S.: Stepped or cascade spillway. Indian Institute of Technology Madras. Textbook (2002)

4. Svendsen, I.; Kirby, J.: Numerical study of a turbulent hydraulic jump. In: Proceedings of the 17th ASCE Engineering Mechanics Conference. University of Delaware. Newark (2004)

5. Chow, V.T.: Open-channel hydraulics. McGraw-Hill, New York (1959) (the classic text)

6. Abbott, M.B.; Marshall, G.; Rodenhuis, G.S.: Amplitudedissipative and phase-dissipative scheme for hydraulic jump simulation. In: Proceedings of the 13th Congress IAHR. International Association of Hydraulic Research, Tokyo, vol. 1, pp. 313-319 (1969)

7. Katopodes, N.D.: Finite element simulation of the undular hydraulic jump. In: Proceedings of the 2nd International Conference on Board the Liner. The Queen Elizabeth 2. New York to Southampton. June/July, 151-162 (1984)

8. Hibberd, S.; Peregrine, D.H.: Surf and run-up on a beach: a uniform bore. J. Fluid Mech. 95(Part2), 323-345 (1979)

9. McCorquodale, J.; Khalifa, A.: Internal flow in hydraulic jumps. J. Hydraul. Eng. 109(5), 684-701 (1981)

10. Basco, D.R.; Adams, J.R.: Drag forces on baffle block in hydraulic jumps. ASCE. J. Hydraul. Eng. 97, 2023-2035 (1971)

11. McCown, B.E.; Cramer, M.S.; Nguyen, S.H.; Bowman, M.E.: A change in wave type modeled by the variable coefficient Kortewegdevries equation. J. Appl. Mech. 52(4), 752-758 (1985)
12. Long, D.; Steffler, P.M.; Rajaratnam, N.: A numerical study of submerged hydraulic jumps. J. Hydraul. Res. 29(3), 293-308 (1991)

13. Qingchao, L.; Drewes, V.: Turbulence characteristics in free and forced hydraulic jumps. J. Hydraul. Res. IAHR 32(4), 877898 (1994)

14. Gharangik, A.; Chaudhry, M.: Numerical simulation of hydraulic jump. J. Hydraul. Eng. 117(9), 1195-1211 (1991)

15. Wang, J.W.; Liu, R.X.: The composite finite volume method on unstructured triangular meshes for $2 \mathrm{D}$ shallow water equations. Intl. J. Numer. Methods Fluids 37(8), 933-949 (2001)

16. Unami, K.; Kawachia, T.; Munir, M.; Itagaki, H.: Estimation of diffusion and convection coefficients in an aerated hydraulic jump. Adv. Water Resour. 23, 475-481 (2000)

17. Yoo, S.; Hong, M.; Wang, H.: 3-Dimensional numerical study of a flow patterns around a multipurpose dam. In: Proceedings of International Conference on Hydro Informatics. Cardiff, UK, pp. 353-357 (2002)

18. Zhao, Q.; Misra, M.; Svendsen, S.; Kirby, I.: Numerical study of a turbulent hydraulic jump. In: 17th ASCE Engineering Mechanics Conference. University of Delaware. Newark (2004)

19. Zhao, Q.; Misra, S.K.: Numerical study of a turbulent hydraulic jump. In: 17th ASCE Engineering Mechanics Conference. University of Delaware (2004)

20. Pirestani, M.R.; Razmkhah, A.; Ghobadi, F.: Effect of Convergent Walls on Energy Dissipation in Stilling Basin by Physical Modeling. Master thesis, Department of Civil Engineering, South Tehran Branch, Islamic Azad University, Tehran, Iran (2010)

21. Report of Water Resources Institute in Iran.: Hydraulic model of Nazloochay dam. Project Code. HSM 8403 (2006)

22. Hirt, C.W.; Nichols, B.D.: Volume of fluid (VOF) method for the dynamics of free boundaries. J. Comput. Phys. 39(1), 201225 (1981)

23. Rodi, W.: Turbulence Models and Their Application in Hydraulics. CRC Press, New York (1993)

24. Fluent 6.0 User's Guide. November 28 (2001)

25. Hirt, C.W.: Modeling Turbulent Entrainment of Air at a Free Surface. Flow Science. Inc. FSI-03-TN61 (2003)

26. Sabaagh-Yazdi, S.R.; Rostami, F.: Turbulent modeling effects on finite volume solution of three dimensional aerated hydraulic jumps using volume of fluid. In: 12th WSEAS International Conference on APPLIED MATHEMATICS. Cairo. Egypt. 29-31 December 2007

27. Isfahani, A.H.G.; Brethour, J.M.: On the implementation of twoequation turbulence models in FLOW-3D. Flow Science. FSI-09TN86 (2009) 